\section{Technology drive}

\author{
Maurice V. Wilkes
}

Computer: A History of the Information Machine. By Martin Campbell-Kelly and William Aspray. BasicBooks: 1996. Pp. 342. \$28.

THE authors offer this work as a popular history of the computer. It starts with three chapters about what went on in offices before computers existed, with the authors pointing out quite properly that information processing did not start with computers. Then come three chapters on the work of the early pioneers of electronic computers leading to the development of the computer industry. The next group of three chapters contains a selective history of the main innovations that came between the end of the Second World War and the advent of the first microprocessors. The final three chapters trace the progress of microcomputers from around 1975, when they were mainly of interest to amateurs, to the arrival of the professional personal computer. By that time, software rather than hardware had become the important

\section{IMAGE UNAVAILABLE FOR COPYRIGHT REASONS}

Spot the Difference - Babbage's engines bore little resemblance to the computers of today.

thing. The book ends with a chapter on the Internet and the World-Wide Web.

Inevitably, one judges a wide-ranging work such as this by the way it deals with topics of which one has specialist knowledge. I found that the treatment of the pioneering work between 1943 and 1946 at the University of Pennsylvania was good; I was much less happy with the section on Charles Babbage in chapter 3 , although the comments about Lady Lovelace are well in line with the opinion of those best able to judge.

Babbage's manuscript notebooks are very far from being filled with "impenetrable scribbling" as the authors assert; in fact, Babbage's reputation today among interested scholars rests largely on the unpublished material they contain.

The first machine that Babbage proposed, the Difference Engine, was limited to the tabulation of polynomials, whereas the Analytical Engine that followed it would have been a genuine general- purpose computer. I entirely fail to follow the authors when they state that the Analytical Engine would have served no purpose that the Difference Engine could not have satisfied and that no-one would have wanted it. Nor do I follow their speculations on the exact reasons why the British government of 1842 declined to revive the dormant Difference Engine project with fresh injections of cash.

It is surely wrong to say that Babbage formally asked the government to finance the building of the Analytical Engine. What he did undoubtedly feel was that, given his work on that engine, he was by 1842 in a position to design a better difference engine; a few years later he spent much effort in preparing detailed plans for what he called Difference Engine No. 2.

The first 20 pages of chapter 4 deal with the pioneering work in electronic computers done at the University of Pennsylvania in the mid-1940s. This led first to the ENIAC and then to the proposals on which the modern stored-program computer is based. The authors are clearly aware of sensitive areas where there have been differences of opinion and where feelings have sometimes run high, and they are evidently concerned to tread with care. I think they have been successful. The perceptive reader will come away with a picture that is well balanced in all essentials and with some feeling for the controversies.

This book is not a history of computer technology, nor is it a history of the ideas behind the technology. The authors' interest is in what may be called small-scale economic history: that is, the economic history of one particular industry. Much space is devoted to the ups and downs of companies, the manoeuvres of their senior managements, and their marketing policies. It would seem to have been a deliberate decision on the part of the authors to slant the book in this way. Yet from the beginning it has been technology that has driven the industry, and I wish that this fact could have been brought out more clearly.

The early computers were painfully lacking in reliability, speed and storage capacity, but they were such miracle-workers that scientific researchers were eager to exploit them. But it was obvious to everybody what needed to be done and there were plenty of able and innovative research engineers anxious to get on with the job. Progress was slow at first, but by the late 1960 s the rate of technical progress on the hardware front was nicely matched to what the industry could handle. Great strides were made with both minicomputers and mainframes. The industrial leaders felt that they were firmly in control.

All went well until the late 1980 s when progress in the semiconductor industry began to run away. More and more transistors could be put on a single silicon chip and, as the individual transistors were smaller, it followed from the laws of physics that they ran faster. The result was that by 1986 it had become possible to build desktop computers that would out-perform the much larger, heavier and more expensive minicomputers and even begin to threaten mainframes. Overnight, the production facilities and organizational structures that had been built up for the manufacture of minicomputers became millstones around their owners' necks. The captains of industry, who had felt so confident, were still at their posts, but they were no longer in control of events. The painful consequences for the older companies in the industry are still in the memory of everybody concerned. Many companies collapsed while others, including the largest companies, underwent severe downsizing.

The book is intended neither for serious students of computer history nor for those interested in the history of ideas, although undoubtedly some of them will find certain sections of interest. As a popular book, however, it is to be welcomed, and I would expect it to do well.

Maurice V. Wilkes is at Olivetti Research Ltd, 24a Trumpington Street, Cambridge CB2 $1 Q A, U K$.

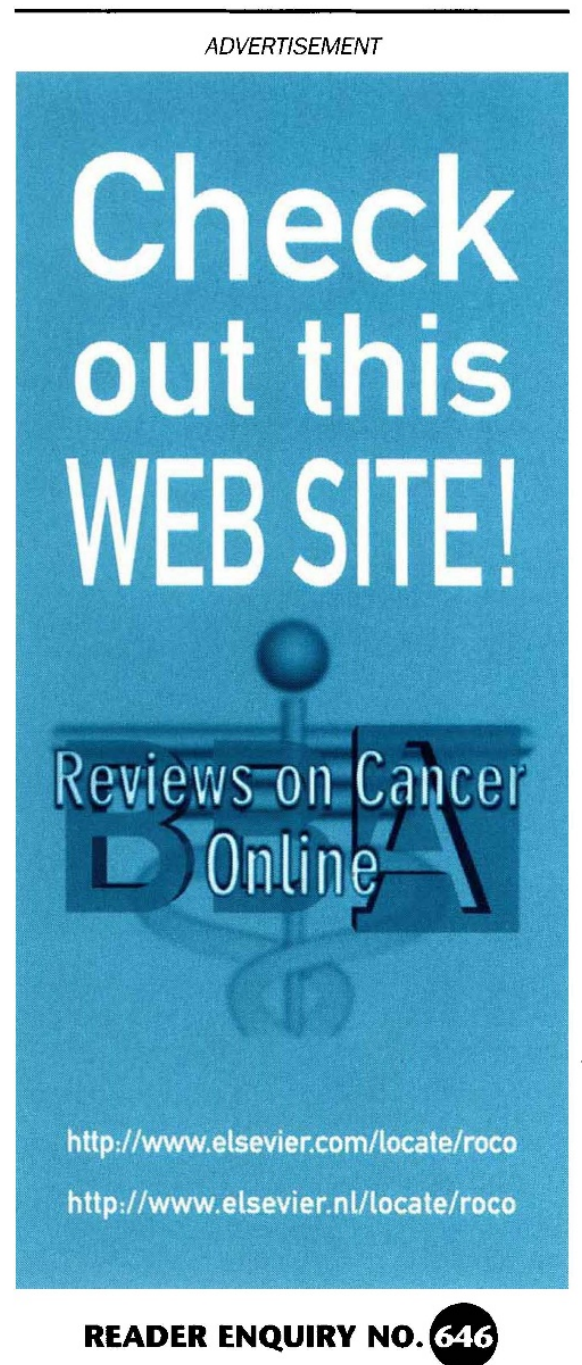

